\title{
Mutant prevention concentrations of ciprofloxacin against urinary isolates of Escherichia coli and Klebsiella pneumoniae
}

\author{
Ziad Daoud ${ }^{1}$, Elie Salem Sokhn², Eid Azar ${ }^{1}$, Khalil Masri $^{3}$, Shira Doron ${ }^{4}$ \\ ${ }^{1}$ Faculty of Medicine and medical Sciences, University of Balamand, Tripoli, Lebanon \\ ${ }^{2}$ Faculty of Health and Medical Sciences, University of Surrey, Guildford, United Kingdom \\ ${ }^{3}$ Infectious Diseases Department, Centre Hospitalier du Nord, Zgharta, Lebanon \\ ${ }^{4}$ Geographic Medicine and Infectious Diseases division, Tufts Medical Center, Boston, MA,United States
}

\begin{abstract}
Introduction: The aim of this work was to study the ability of ciprofloxacin to restrict the development of resistant mutants of Escherichia coli and Klebsiella pneumoniae through determination of the Mutant Prevention Concentration (MPC).

Methodology: We studied 140 strains of $E$. coli and 86 strains of $K$. pneumoniae with different profiles of sensitivity to fluoroquinolones and extended spectrum beta lactamase (ESBL) production. The MPCs were determined using an inoculum of $10^{10} \mathrm{CFU} / \mathrm{ml}$ in Mueller-Hinton agar plates with serial concentrations of ciprofloxacin.

Results: Ciprofloxacin-susceptible ESBL-producing strains showed a higher MPC for ciprofloxacin $(\mathrm{P}<0.001)$ than ciprofloxacin-susceptible non ESBL-producing strains, while ciprofloxacin-resistant ESBL-producing and non ESBL-producing strains did not significantly differ. The presence of $q n r$ variants was associated with elevated MPCs. This was observed for both tested organisms.

Conclusions: Our study helps to explain the frequent finding of resistance to fluoroquinolones in ESBL-producing strains. Consequently, the use of concentrations of ciprofloxacin higher than the MIC in order to prevent the recovery and growth of resistant mutants is recommended.

Key words: mutant prevention concentration, ESBL, ciprofloxacin, Escherichia coli, Klebsiella pneumoniae
\end{abstract}

J Infect Dev Ctries 2014; 8(2):154-159. doi:10.3855/jidc.3164

(Received 21 November 2012 - Accepted 22 May 2013)

Copyright $(\odot 2014$ Daoud et al. This is an open-access article distributed under the Creative Commons Attribution License, which permits unrestricted use, distribution, and reproduction in any medium, provided the original work is properly cited.

\section{Introduction}

Quinolones are one of the most widely used antibiotics to treat infections caused by Escherichia coli and Klebsiella pneumoniae in humans and in animals [1]. However, resistance to these antibiotics has increased in the recent years and is especially high in extended spectrum beta lactamase (ESBL) producing strains [2,3]. The transferable qnr determinants were identified in Gram negative clinical isolate plasmid; these genes encode for a pentapeptide repeat protein that binds to and protects type II DNA topoisomerases from inhibition by quinolones [4]. Five types of qnr genes have been reported: qnrA, qnrB, qnrS, qnrC, and qnrD, and some of them have several allelic variants [5,6]. In addition to the qnr genes, several new mechanisms of plasmid-mediated quinolone resistance (PMQR) genes have been discovered during the past decade, including the aac(6')-Ib-cr and qepA genes [7].

The Mutant Prevention Concentration (MPC) was defined as a useful parameter that prevents/interferes with the emergence and growth of resistant mutants [8]. These resistant subpopulations may be associated with treatment failures and emergence of resistance [9]. The MPC represents a concentration threshold above which proliferation of resistant mutants is expected to be rare. When used to describe quinolones, the MPC represents the drug concentration that would require an organism to possess two resistance mutations in order to grow in the presence of the drug, and it is equal to the MIC of the most resistant singlemutation organism in a heterogeneous population.

The mutant selection window defines the range of drug concentrations in which resistant mutants are easily produced. The upper limit of the mutant selection window is the MPC, and the lower limit is the MIC. Thus, the size of the ratio MPC/MIC, also known as the Mutant Prevention Index (MPI), represents the size of this dangerous concentration window.

The Middle East region has witnessed an important increase of resistance in Gram negative 
bacilli; many reports describe a significant emergence of extended spectrum beta lactamase producing Escherichia coli and Klebsiella pneumoniae in Lebanon $[10,14]$.

The aim of our study is to use this new parameter (MPC) to study the ability of various concentrations of the fluoroquinolone ciprofloxacin to limit the development of resistant mutants in clinical isolates of E. coli isolated for urinary tract infections.

\section{Methodology}

Bacterial strains

We studied 140 strains of E. coli and 86 strains of $K$. pneumoniae divided into the following groups: 47 strains of E. coli and 29 strains of $K$. pneumoniae susceptible to ciprofloxacin non ESBL producers, 34 strains of E. coli and 26 strains of $K$. pneumoniae resistant to ciprofloxacin, non ESBL producers, 30 strains of E. coli and 19 strains of K. pneumoniae susceptible to ciprofloxacin ESBL producers, and 29 $E$. coli and 12 strains of $K$. pneumoniae resistant to ciprofloxacin ESBL producers. All strains tested were isolated from urine samples obtained from patients at the Saint George Hospital-UMC in Beirut between January 2008 and January 2010. To avoid duplicates, the isolates coming from the same patient, same site of infection with the same susceptibility profiles were excluded from the study.

\section{Antimicrobial testing and mechanisms of resistance}

The Minimum Inhibitory Concentrations (MIC) and the Mutant Prevention Concentrations (MPC) of ciprofloxacin against the bacterial isolates were determined. The MIC was determined by the macrodilution method and the antibiotic susceptibility testing was performed using the Kirby-Bauer technique according to the Clinical and Laboratory Standards Institute (CLSI) [15].The antibiotic concentrations ranged between 64 and $0.003 \mu \mathrm{g} / \mathrm{ml}$.

To select the ESBL producing strains subjected to our study, we did a phenotypic screening using the Etests cefotaxime/cefotaxime + clavulanic acid and ceftazidime/ceftazidime + clavulanic acid (AB Biodisk, Solna, Sweden) and by the Disk Synergy Method using cefotaxime $(30 \mu \mathrm{g})$, cefotaxime/clavulanic acid (30/10 $\mu \mathrm{g}, 30 \mu \mathrm{g})$, ceftazidime $(30 \mu \mathrm{g})$ and ceftazidime/clavulanic acid 30/10 $\mu \mathrm{g}$ ) (Oxoid, Basingstoke, UK) [16].The strains that gave a positive result were included in the study and a subsequent genotypic testing was performed to identify the ESBL produced by these organisms.
PCR detection and sequencing of blaTEM, blaSHV, blaCTX-M, and blaOXA-1genes

Polymerase chain reaction (PCR) and sequence analysis were used in order to identify the gene responsible for the ESBL phenotype in all strains. It should be noted that not all genes were sequenced in strains where multiple beta-lactamase genes existed. The isoelectric points (pIs) of the beta-lactamases were used to predict the most likely ESBL candidate, and this gene was sequenced. For instance, if a strain contained blaTEM and the IEF results showed a betalactamase with a pI of 5.4, an assumption was made that this beta-lactamase most likely represented the non-ESBL TEM-1 and the other gene was sequenced. All strains were examined for the presence of blaTEM, blaSHV, blaCTX-M, and blaOXA-1 using PCR conditions as previously described $[16,18]$. The sequence of the blaTEM, blaSHV, and blaCTX-M ORF PCR products were determined by using a Big Dye PCR (Perkin-Elmer/Cetus) and analyzed on an ABI Prism 3130 DNA Genetic Analyzer (PerkinElmer Applied Biosystems, Foster City, USA).

\section{Screening and sequencing of qnr gene}

Seventy five strains of E.coli and 50 strains of Klebsiella spp. were screened for the presence of the $q n r$ gene by multiplex PCR as previously described ([19]. Sequencing was performed as described above.

\section{Mutant Prevention Concentration}

The MPC is defined as the concentration at which no colony was recovered when more than $10^{10} \mathrm{CFU}$ were applied to agar plates. The determination of the MPC was performed as described by Blondeau [20]. First, the bacterial isolates were grown on Mueller Hinton agar plates (bioMérieux, Marcy l'Etoile, France) and incubated overnight at $37^{\circ} \mathrm{C}$. A bacterial suspension of $\geq 3 \times 10^{10} \mathrm{CFU} / \mathrm{mL}$ was prepared. For the MPC determination, $100 \mu \mathrm{l}$ of this concentrated bacterial suspension was used to inoculate each fluoroquinolone plate. These plates were incubated at $37^{\circ} \mathrm{C}$ and were screened for colonies every 24 hours over 2 days to ensure that the colony number had stabilized. The antibiotic concentrations studied ranged between 100 and $0.003 \mathrm{mg} / \mathrm{l}$.

To see whether the MIC and the MPC of the different groups belonged to the same distribution, the Mann-Whitney $\mathrm{U}$ test was used, with $\mathrm{p}<0.05$ considered statistically significant (SPSS 11.0). 


\section{Results}

The MIC and MPC results of ciprofloxacin for $E$. coli and $K$. pneumoniae are shown in Table 1 . No significant differences were seen between the MICs of this antibiotic in ciprofloxacin-susceptible ESBLproducing and ESBL-non producing strains for both $E$. coli and $K$. pneumoniae. As well, no significant differences were observed between the MICs in ciprofloxacin-resistant ESB-producing and non-ESBL producing strains of E. coli and K. pneumoniae.

As shown in Table 2, in all isolates, the pI 7.3, 8.2, and 8.6 beta-lactamases demonstrated cefotaxime- and ceftazidime hydrolyzing activity under the conditions used in the assay. Some other beta-lactamases that were observed as separate IEF bands in protein extracts of studied isolates, such as those with pIs of 5.4 (probably TEM-1) and 7.6 (probably species specific $K$. pneumoniae enzymes) did not show cefotaxime- or ceftazidime hydrolyzing activity in the bioassay under the conditions used.

Ciprofloxacin-susceptible ESBL-producing strains showed a higher MPC for ciprofloxacin $(\mathrm{P}<0.001)$ than those strains that were non ESBLproducing,while Ciprofloxacin-resistant ESBLproducing and non ESBL-producing strains did not show a significant difference. This was observed for both tested organisms. On the other hand, 2 strains $(10 \%)$ of ESBL(+) E.coli Susceptible to ciprofloxacin and 3 strains $(17.6 \%)$ of ESBL(+) E.coli Resistant to ciprofloxacin were $q n r(+)$, while only one ESBL(-) E.coli resistant to ciprofloxacin was qnr(+). Klebsiella spp. gave a positive result for this gene in both ESBL producers and non producers as shown in Table 3 . The highest number and percentage of $q n r(+)$ was detected in ESBL (+) Klebsiella spp. resistant to cCiprofloxacine. The most common variants were A1 and B4 with the latter occurring mostly in Klebsiella spp. The total number of isolates in which qnr genes were detected was 12 E.coli $(16 \%)$ and 20 Klebsiella spp (40\%). All these strains scored the highest MICs and MPCs in their respective populations.

The Mutation Prevention Index (MPI=MPC/MIC) for ciprofloxacin (Table 4) indicates the need for concentrations much higher than the MIC to prevent the growth of resistant strains of $E$. coli and $K$. pneumoniae. In view of these relatively high ratios, even in the strains that were susceptible to ciprofloxacin, treatment failure can be better explained.

Table 1: MIC and MPC profiles of ciprofloxacin against ESBL producers and non producers Escherichia coli and Klebsiella pneumoniae

\begin{tabular}{|c|c|c|c|c|c|c|c|c|}
\hline & \multicolumn{4}{|c|}{ Escherichia coli } & \multicolumn{4}{|c|}{ Klebsiella sp. } \\
\hline & \multicolumn{2}{|c|}{$\begin{array}{l}\text { Susceptible to } \\
\text { Ciprofloxacin }\end{array}$} & \multicolumn{2}{|c|}{$\begin{array}{c}\text { Resistant to } \\
\text { Ciprofloxacin }\end{array}$} & \multicolumn{2}{|c|}{$\begin{array}{l}\text { Susceptible to } \\
\text { Ciprofloxacin }\end{array}$} & \multicolumn{2}{|c|}{$\begin{array}{c}\text { Resistant to } \\
\text { Ciprofloxacin }\end{array}$} \\
\hline Total nb. & $\begin{array}{l}\text { ESBL+ } \\
(\mathrm{n}=30)\end{array}$ & $\begin{array}{l}\text { ESBL- } \\
(\mathrm{n}=47)\end{array}$ & $\begin{array}{l}\text { ESBL+ } \\
(\mathrm{n}=29)\end{array}$ & $\begin{array}{l}\text { ESBL- } \\
(\mathrm{n}=34)\end{array}$ & $\begin{array}{l}\text { ESBL+ } \\
(n=19)\end{array}$ & $\begin{array}{l}\text { ESBL- } \\
(\mathrm{n}=29)\end{array}$ & $\begin{array}{l}\text { ESBL+ } \\
(\mathrm{n}=12)\end{array}$ & $\begin{array}{l}\text { ESBL- } \\
(\mathrm{n}=26)\end{array}$ \\
\hline СТX-M-15 & $(n=24)$ & -- & $(n=26)$ & -- & $(n=10)$ & -- & $(n=6)$ & -- \\
\hline SHV-5a & $(n=6)$ & -- & $(n=3)$ & -- & $(\mathrm{n}=9)$ & -- & $(n=6)$ & -- \\
\hline $\mathrm{MIC}_{50}$ & 0.25 & 0.125 & 32 & 16 & 0.5 & 0.125 & 32 & 32 \\
\hline $\mathrm{MIC}_{90}$ & 1.5 & 1 & 64 & 64 & 2 & 1.5 & 64 & 64 \\
\hline $\mathrm{MPC}_{50}$ & 4 & 0.2 & 50 & 50 & 8 & 0.2 & 70 & 60 \\
\hline$\left(\mathrm{xMIC}_{50}\right)$ & $(16 \times \mathrm{MIC})$ & (1.6 x MIC) & (1.6 x MIC) & (3.1 x MIC) & (16 x MIC) & (1.6 x MIC) & $(2.2 \times$ MIC $)$ & $(1.8 \times \mathrm{MIC})$ \\
\hline $\mathrm{MPC}_{90}$ & 12 & 3 & 100 & 100 & 12 & 4 & 100 & 100 \\
\hline$\left(\mathrm{xMIC}_{90}\right)$ & $(8 \times \mathrm{MIC})$ & $(3 \times \mathrm{MIC})$ & (1.6 x MIC) & $(1.6 \times \mathrm{MIC})$ & $(6 \times \mathrm{MIC})$ & $(2.7$ x MIC) & $(1.6 \times \mathrm{MIC})$ & $(1.6 \times \mathrm{MIC})$ \\
\hline
\end{tabular}

Table 2: Beta-Lactamase profiles, ceftazidime and cefotaxime hydrolyzing activities, and ESBL types of the ESBLproducing E.coli and Klebsiella spp.

\begin{tabular}{lccc}
\hline Species & No. of isolates & PIs of the beta-lactamases & ESBL types \\
\hline Escherichia coli & 31 & $8.6,5.4$ & CTX-M-15 \\
Escherichia coli & 19 & $8.6,7.3,5.4$ & CTX-M-15 \\
Escherichia coli & 9 & $8.2,5.4$ & SHV-5a \\
Klebsiella spp. & 16 & $8.6,7.6,5.4$ & CTX-M-15 \\
Klebsiella spp. & 15 & $8.2,7.6,5.4$ & SHV-5a \\
\hline
\end{tabular}

$\mathrm{pI}$ values in boldface indicate beta-lactamases that were positive in the bioassay with ceftazidime and cefotaxime as substrates. 
Table 3: Occurrence and distribution of qnr genes in E.coli and Klebsiella spp.

\begin{tabular}{|c|c|c|c|c|c|c|c|c|c|}
\hline & & \multicolumn{4}{|c|}{ Escherichia coli } & \multicolumn{4}{|c|}{ Klebsiella sp. } \\
\hline & & \multicolumn{2}{|c|}{$\begin{array}{l}\text { Susceptible to } \\
\text { Ciprofloxacin }\end{array}$} & \multicolumn{2}{|c|}{$\begin{array}{l}\text { Resistant to } \\
\text { Ciprofloxacin }\end{array}$} & \multicolumn{2}{|c|}{$\begin{array}{l}\text { Susceptible to } \\
\text { Ciprofloxacin }\end{array}$} & \multicolumn{2}{|c|}{$\begin{array}{l}\text { Resistant to } \\
\text { Ciprofloxacin }\end{array}$} \\
\hline & Tested & $\begin{array}{l}\text { ESBL+ } \\
(\mathrm{n}=20)\end{array}$ & $\begin{array}{l}\text { ESBL- } \\
(\mathrm{n}=20)\end{array}$ & $\begin{array}{l}\text { ESBL+ } \\
(\mathrm{n}=17)\end{array}$ & $\begin{array}{l}\text { ESBL- } \\
(\mathrm{n}=16)\end{array}$ & $\begin{array}{l}\text { ESBL+ } \\
(\mathrm{n}=13)\end{array}$ & $\begin{array}{l}\text { ESBL- } \\
(\mathrm{n}=14)\end{array}$ & $\begin{array}{l}\text { ESBL+ } \\
(\mathrm{n}=10)\end{array}$ & $\begin{array}{l}\text { ESBL- } \\
(\mathrm{n}=13)\end{array}$ \\
\hline & Number (\%) & $2(10.0)$ & $0(0.0)$ & $3(17.6)$ & $1(6.2)$ & $1(7.7)$ & $1(7.1)$ & $5(50)$ & $3(15.3)$ \\
\hline$\lesssim$ & variants & $\begin{array}{l}1(\mathrm{~B} 4), \\
1(\mathrm{~S} 1)\end{array}$ & 0 & $\begin{array}{l}\text { 2(B4), } \\
1 \text { (S1) }\end{array}$ & $1(\mathrm{~A} 1)$ & $1(\mathrm{~A} 1)$ & 1 (B4) & $\begin{array}{l}3(\mathrm{~A} 1), \\
2(\mathrm{~B} 4)\end{array}$ & $2(\mathrm{~A} 1), 1(\mathrm{~B} 4)$ \\
\hline 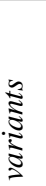 & $\mathrm{MIC} \mu \mathrm{g} / \mathrm{ml}$ & $\begin{array}{l}\text { (B4): } 2 \\
\text { (S1): } 2\end{array}$ & -- & $\begin{array}{l}\text { (B4): } 128 \\
\text { (B4): } 64 \\
\text { (S1): } 64\end{array}$ & (A1): 128 & (A1): 4 & (B4): 2 & $\begin{array}{l}\text { (A1): } 128 \\
\text { (A1): } 64 \\
\text { (A1): } 64 \\
\text { (B4): } 32 \\
\text { (B4): } 64\end{array}$ & $\begin{array}{l}\text { (A1): } 64 \\
\text { (A1): } 64 \\
\text { (B4): } 32\end{array}$ \\
\hline $\begin{array}{l} \pm \\
\vdots \\
\vdots\end{array}$ & $\mathrm{MPC} \mu \mathrm{g} / \mathrm{ml}$ & $\begin{array}{l}\text { (B4): } 12 \\
\text { (S1): } 12\end{array}$ & & $\begin{array}{c}\text { (B4): } 256 \\
\text { (B4): } 128 \\
\text { (S1): } 96\end{array}$ & (A1): 128 & (A1): 12 & (B4): 12 & $\begin{array}{l}\text { (A1): } 256 \\
\text { (A1): } 128 \\
\text { (A1): } 128 \\
\text { (B4):64 } \\
\text { (B4): } 64\end{array}$ & $\begin{array}{l}\text { (A1): } 128 \\
\text { (A1): } 128 \\
\text { (B4): } 64\end{array}$ \\
\hline
\end{tabular}

Table 4: Distribution of the ratio MPC/MIC of Ciprofloxacin against Escherichia coli and Klebsiella pneumoniae

Escherichia coli

\begin{tabular}{|c|c|c|c|c|c|c|c|c|}
\hline & \multicolumn{2}{|c|}{ Susceptible to Ciprofloxacin } & \multicolumn{2}{|c|}{ Resistant to Ciprofloxacin } & \multicolumn{2}{|c|}{ Susceptible to Ciprofloxacin } & \multicolumn{2}{|c|}{ Resistant to Ciprofloxacin } \\
\hline MPC / MIC & $\begin{array}{l}\text { ESBL+ } \\
(\mathrm{n}=30)\end{array}$ & $\begin{array}{c}\text { ESBL- } \\
(\mathrm{n}=47)\end{array}$ & $\begin{array}{l}\text { ESBL+ } \\
(\mathrm{n}=29)\end{array}$ & $\begin{array}{l}\text { ESBL- } \\
(\mathrm{n}=34)\end{array}$ & $\begin{array}{l}\text { ESBL+ } \\
(\mathrm{n}=19)\end{array}$ & $\begin{array}{l}\text { ESBL- } \\
(\mathrm{n}=29)\end{array}$ & $\begin{array}{l}\text { ESBL+ } \\
(\mathrm{n}=12)\end{array}$ & $\begin{array}{l}\text { ESBL- } \\
(\mathrm{n}=26)\end{array}$ \\
\hline$<2$ & 4 & 4 & 10 & 3 & 3 & 3 & 2 & 3 \\
\hline $2.0-4.9$ & 4 & 3 & 5 & 2 & 1 & 2 & 2 & 3 \\
\hline $5.0-8.0$ & 10 & 6 & 3 & 11 & 5 & 5 & 3 & 6 \\
\hline$>8$ & 12 & 34 & 11 & 18 & 10 & 18 & 5 & 14 \\
\hline
\end{tabular}

\section{Discussion}

Strains of E. coli and K. pneumoniae producing ESBL are a major health problem because of the difficulty in treating infections caused by these microorganisms as they are resistant to most betalactam antibiotics (except carbapenems). In addition, they may be resistant to other groups of antimicrobial agents [18]. Because ESBL-producing enterobacteriaceae frequently cause urinary tract infections, cross resistance with fluoroquinolones is a very challenging issue since intravenous therapy is not recommended in these infections except for the most serious (Pyelonephritis).

Our study showed that subpopulations of ciprofloxacin-susceptible ESBL-producers have the potential to be more difficult to treat with fluoroquinolones than the non-ESBL producers, because while the MICs are similar, the MPCs for ciprofloxacin are higher in the ESBL producing strains.

This study confirms that ESBL-producing strains, mainly those that are sensitive to fluoroquinolones, have subpopulations that are resistant to these compounds and therefore can be easily selected during antimicrobial therapy, this has been suggested by another previous study [21]. Although the occurrence of $q n r$ genes was higher in the group of bacteria resistant to ciprofloxacin, they were associated with the highest MIC and MPC. These strains were responsible for the elevated $\mathrm{MPC}_{90}$. Then removed from the group, both $\mathrm{MIC}_{90}$ and $\mathrm{MPC}_{90}$ were significantly decreased (data not shown). On the other hand, and according to the CLSI guidelines, $q n r$ provides resistance to nalidixic acid but only reduced susceptibility to the fluoroquinolones. It has been shown that qnr may facilitate the recovery of resistant mutants with higher levels of quinolones resistance by increasing the MPC [7]. This was obvious in our results mainly in the groups of bacteria that show phenotypic resistance to ciprofloxacin. More studies with larger bacterial populations are needed to explain whether a relationship between $q n r$ variants and MPC exists. In addition, the detection of other mechanisms of resistance needs to be studied as well, mainly the 
aac(6')-lb-cr in view of its high ability to increase MPCs.

Therefore, treatment with fluoroquinolones should be undertaken with caution and given in higher doses in order to produce higher concentrations in the site of infection (ideally above the MPC) to prevent the selection of these subpopulations, especially in the case of ESBL producing organisms.

Most of the ESBLs produced by E.coli were due to CTX-M-15 while the Klebsiella spp. isolates had an approximately equal number of CTX-M-15 and SHV5a (as shown in Table 2) as the cause of ESBL production. This pattern does not seem to have an impact on the ciprofloxacin MPC since these two enzymes are evenly distributed between the ciprofloxacin-susceptible and the ciprofloxacinresistant populations. In this context, it would be beneficial to conduct molecular studies to assess the mechanism of resistance to ciprofloxacin in the studied population.

Our data helps also explain the therapeutic failures and suggests the need to employ methodologies that allow the detection of these subpopulations in clinical laboratories since traditional methods are not effective.

The concept of MPC could be used to make decisions about dosing regimen with respect to the potential for the selection and enrichment of mutants. It has been suggested that MPC could be useful in telling if it is still reasonable to use monotherapy with little chance of resistance emerging or whether shift to a combination therapy is needed [20,21]. We have shown that E. coli and Klebsiella spp. UTI isolates producing ESBLs, although with a susceptible profile to ciprofloxacin, had elevated MPCs. For these strains, dosing above MPC during monotherapy is a must in order to avoid selection of the mutants, however, the approved dosing regimen and drug toxicity constitute a major challenge for this issue.

The use of concentrations higher than the MPC in order to prevent the recovery and growth of resistant mutants should be considered within the context of the pharmacokinetics and pharmacodynamics of the drug in question. In addition, we think that determination of MPC should be performed in clinical microbiology laboratories with resources to do so, in view of its importance and significance.

\section{Acknowledgements}

This work was supported by a grant from the Lebanese National Council for Scientific Research

\section{References}

1. Webber M, Piddock LJ (2001) Quinolone resistance in Escherichia coli. Vet Res 32: 275-284.

2. Sorlózano A, Gutiérrez J, de Dios Luna J, Oteo J, Liébana J, Soto MJ, Piédrola G (2007) High presence of extendedspectrum beta-lactamases and resistance to quinolones in clinical isolates of Escherichia coli. Microbiol Res 162: 347354.

3. Pitout JDD, Nordmann P, Laupland KB, Poirel L (2005) Emergence of Enterobacteriaceae producing Extended Spectrum Beta Lactamases (ESBLs) in the community. J Antimicrob Chemoth 56: 52-59.

4. Tran JH, Jacoby GA (2002) Mechanism of plasmidmediated quinolone resistance. Proc Natl Acad Sci 99: 5638-5642

5. Cavaco LM, Hasman H, Xia S, Aarestrup FM (2009) qnrD, a novel gene conferring transferable quinolone resistance in Salmonella enterica serovar Kentucky and Bovismorbificans strains of human origin. Antimicrob Agents Chemother. 53: 603-608.

6. Jacoby G, Cattoir V, Hooper D, Martinez-Martinez L, Nordmann P, Pascual A, Poirel L, Wang M (2008) Qnr Gene nomenclature. Antimicrob Agents Chemother. 52: 2297-2299

7. Robicsek A, Jacoby GA, Hooper DC (2006) The worldwide emergence of plasmid-mediated quinolone resistance. Lancet Infect Dis 6: 629-640.

8. Zhao X, and Drlica K (2001) Restricting the selection of antibiotic-resistant mutants: a general strategy derived from fluoroquinolones studies. Clin Infect Dis 33: S147-S56.

9. Dong Y, Zhao X, Domagala J, Drlica K (1999) Effect of fluoroquinolone concentration on selection of resistant mutants of Mycobacterium bovis BCG and Saphylococcus aureus. Antimicrob Agents Chemother. 43: 1756-1758.

10. Kanj SS, Corkill JE, Kanafani ZA, Araj GF, Hart CA, Jaafar R, Matar GM (2008) Molecular characterisation of Extended Spectrum Beta Lactamase-producing Escherichia coli and Klebsiella spp. isolates at a tertiary-care center in Lebanon. Clin Microbiol Infect 14: 501-504.

11. Daoud Z, Moubareck C, Hakime N, Doucet-Populaire F (2006) Extended Spectrum Beta Lactamase producing Enterobacteriaceae in Lebanese ICU patients: epidemiology and patterns of resistance. J Gen Appl Microbio 52: 169-178

12. Moubareck C, Daoud Z, Hakimé NI, Hamzé M, Mangeney N, Matta H, Mokhbat JE, Rohban R, Sarkis DK, DoucetPopulaire F (2005) Countrywide spread of community- and hospital-acquired Extended Spectrum Beta Lactamase (CTXM-15)-producing Enterobacteriaceae in Lebanon. J Clin Microbiol 43: 3309-3313.

13. Matar GM, Al Khodor S, El-Zaatari M, Uwaydah M (2005) Prevalence of the genes encoding Extended Spectrum Beta Lactamases in Escherichia coli resistant to beta-lactam and non-beta-lactam antibiotics. Ann Trop Med Parasit 99: 413417.

14. Daoud Z, Hakime N (2003) Prevalence and susceptibility patterns of Extended Spectrum Beta Lactamase-producing Escherichia coli and Klebsiella pneumoniae in a general university hospital in Beirut, Lebanon. Rev Esp Quimioter 16: 233-238.

15. Clinical and Laboratory Standards Institute (2010) Methods for dilution Antimicrobial Susceptibility Tests for Bacteria That Grow Aerobically: Approved Standard- Eighth Edition 2010. CLSI document M07-A8 : 26, no.2. Wayne, PA: CLSI.

16. Casin I, Breuil J, Brisabois A, Moury F, Grimont F, Collatz E (1999) Multidrug-resistant human and animal Salmonella 
typhimurium isolates in France belong predominantly to a DT104 clone with the chromosome- and integron-encoded beta-lactamase PSE-1. J Infect Dis 179: 1173-1182.

17. Mulvey MR, Soule G, Boyd D, Demczuk W, Ahmed R (2003) Characterization of the first extended-spectrum betalactamase-producing Salmonella isolate identified in Canada. J Clin Microbiol 41: 460-462.

18. Perilli M, Dell'Amico E, Segatore B, de Massis MR, Bianchi B, Luzzaro F, Rossolini GM, Toniolo A, Nicoletti G, Amicosante G (2002) Molecular characterization of extendedspectrum beta-lactamases produced by nosocomial isolates of Enterobacteriaceae from an Italian nationwide survey. J Clin Microbiol 40:611-614.

19. Bouchakkour M, Zerouali K, Gros Claude JDP, Amarouch H, El Mdaghri N, Courvalin P, Timinouni M (2010) Plamsid mediated quinolone resistance in expanded spectrum beta lactamase producing Enterobacteriaceae in Morocco. J Infect Dev Ctries 4: 799-803.
20. Blondeau JM, Zhao X, Hansen G, Drlica K (2001) Mutant prevention concentrations of fluoroquinolones for clinical isolates of Streptococcus pneumoniae. Antimicrob Agents Chemother 45: 433-438.

21. Marcusson LL, Olofsson SK, Lindgren PK, Cars O, Hughes D (2005) Mutant prevention concentrations of ciprofloxacin for urinary tract infection isolates of Escherichia coli. J Antimicrob Chemother 55: 938-943.

\section{Corresponding author}

Ziad Daoud

Faculty of Medicine and medical Sciences

University of Balamand

POBox: 100, Tripoli, Lebanon

Telephone: +961.3 .729927$

Email: ziad.daoud@balamand.edu.lb

Conflict of interests: No conflict of interests is declared. 